\title{
hsa-mir-30c promotes the invasive phenotype of metastatic breast cancer cells by targeting NOV/ CCN3
}

Jason R Dobson ${ }^{1,2}$, Hanna Taipaleenmäki ${ }^{1,3}$, Yu-Jie Hu ${ }^{1}$, Deli Hong ${ }^{1,4}$, Andre J van Wijnen ${ }^{1,5}$, Janet L Stein ${ }^{1,4}$, Gary S Stein ${ }^{1,4}$, Jane B Lian ${ }^{1,4^{*}}$ and Jitesh Pratap ${ }^{1,6}$

\begin{abstract}
Background: For treatment and prevention of metastatic disease, one of the premier challenges is the identification of pathways and proteins to target for clinical intervention. Micro RNAs (miRNAs) are short, non-coding RNAs, which regulate cellular activities by either mRNA degradation or translational inhibition. Our studies focused on the invasive properties of hsa-mir30c based on its high expression in MDA-MB-231 metastatic cells and our bioinformatic analysis of the Cancer Genome Atlas that identified aberrant hsa-mir-30c to be associated with poor survival.
\end{abstract}

Methods: Contributions of hsa-mir-30c to breast cancer cell invasion were examined by Matrigel invasion transwell assays following modulation of hsa-mir-30c or hsa-mir-30** levels in MDA-MB-231 cells. hsa-mir-30c in silico predicted targets linked to cell invasion were screened for targeting by hsa-mir-30c in metastatic breast cancer cells by RT-qPCR. The contribution to invasion by a target of hsa-mir-30c, Nephroblastoma overexpressed (NOV), was characterized by siRNA and invasion assays. Significant effects were determined using Student's T-tests with Welch's correction for unequal variance.

Results: MCF-7 and MDA-MB-231 cells were used as models of poorly invasive and late-stage metastatic disease, respectively. By modulating the levels of hsa-mir-30c in these cells, we observed concomitant changes in breast cancer cell invasiveness. From predicted targets of hsa-mir-30c that were related to cellular migration and invasion, NOV/CCN3 was identified as a novel target of hsa-mir-30c. Depleting NOV by siRNA caused a significant increase in the invasiveness of MDA-MB-231 cells is a regulatory protein associated with the extracellular matrix.

Conclusions: NOV/CCN3 expression, which protects cells from invasion, is known in patient tumors to inversely correlate with advanced breast cancer and metastasis. This study has identified a novel target of hsa-mir-30c, NOV, which is an inhibitor of the invasiveness of metastatic breast cancer cells. Thus, hsa-mir-30c-mediated inhibition of NOV levels promotes the invasive phenotype of MDA-MB-231 cells and significantly, the miR-30/NOV pathways is independent of RUNX2, a known target of hsa-mir-30c that promotes osteolytic disease in metastatic breast cancer cells. Our findings allow for mechanistic insight into the clinical observation of poor survival of patients with elevated hsa-mir-30c levels, which can be considered for miRNA-based translational studies.

Keywords: miRNA, Hsa-mir-30c breast cancer, Invasion, Metastasis, NOV/CCN3

\footnotetext{
* Correspondence: jane.lian@uvm.edu

'Department of Cell and Developmental Biology, University of Massachusetts

Medical School, 55 Lake Ave, North, Worcester, MA 01655, USA

${ }^{4}$ Current address: Department of Biochemistry and Vermont Cancer Center,

University of Vermont College of Medicine, 89 Beaumont Avenue, Burlington,

VT 05405-0068, USA

Full list of author information is available at the end of the article
}

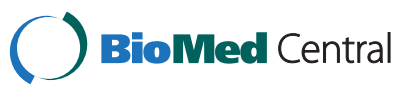

(c) 2014 Dobson et al.; licensee BioMed Central Ltd. This is an Open Access article distributed under the terms of the Creative Commons Attribution License (http://creativecommons.org/licenses/by/4.0), which permits unrestricted use, distribution, and reproduction in any medium, provided the original work is properly credited. The Creative Commons Public Domain Dedication waiver (http://creativecommons.org/publicdomain/zero/1.0/) applies to the data made available in this article, unless otherwise stated. 


\section{Background}

Breast cancer is the most commonly diagnosed disease among women. Aggressive breast cancers have high potential to become metastatic, a transition that makes clinical intervention difficult. In recent years, many of the molecular mechanisms that facilitate a more invasive or metastatic state have been characterized [1-3]. It has been observed that the transcriptome of primary breast cancer cells with a predisposition for metastasis can be distinguished from non-metastatic breast cancer cells [4]. This indicates that steady-state mRNA levels are altered in pre-metastatic tissue to promote metastasis. Therefore, it is critical to define the events leading to and maintaining a metastatic transcriptional landscape of metastatic breast cancer cells.

Assessing a cell's transcriptome using RNA-seq or hybridization arrays provides measurement of the steadystate levels of cellular mRNAs. Cellular mRNA levels are controlled at multiple levels: transcriptional rate; mRNA processing and export; mRNA stability; and translational rate. miRNAs are small non-coding RNAs that posttranscriptionally regulate mRNA levels, many of which are critical for development [5]. Similar to mRNAs, the steady-state levels of miRNAs are also altered in cancerous tissues as compared to normal cells. Further, just as for protein coding RNAs, many non-coding RNAs have the capacity to function as tumor suppressors and oncogenes (often referred to as onco-miRs) [6,7]. miRNAs are also involved in cancer cell metastasis (metasta-miRs), and regulate key physiological steps in the metastatic process of many cancers, including breast [2,8-11]. Hence, characterizing members of this class of non-coding RNAs is important in our understanding of breast cancer development and progression.

We queried publicly available data from TCGA Breast Cancer project [12] for aberrant miRNAs, and observed that hsa-mir-30c is elevated in expression level or copy number in approximately $4 \%$ or breast cancer patients. Importantly, these patients have significantly poorer survival than patients with normal hsa-mir-30c, which suggests that hsa-mir-30c may be a key factor in breast cancer progression. Using a cell-based model, we observed an association between cellular invasion and high levels hsa-mir-30c, which led us to hypothesize that the observed clinical mortality phenotype associated with aberrant hsa-mir-30c was as a result of hsa-mir-30c regulation of breast cancer cell invasion. To address this hypothesis, we examined factors targeted by hsa-mir-30c that regulate breast cancer cell invasion. We investigated potential cross talk between a factor known to be targeted by miR-30c, RUNX2 [13], which promotes metastasis and osteolytic disease [14]. Further, because there are still many unknown players promoting the metastatic phenotype of advanced breast cancer, we addressed other targets of hsa-mir-30c, first by in silico analyses for targets linked to cellular invasion, then functional investigation of these potential targets.

Our key findings demonstrated that highly metastatic MDA-MB-231 breast cancer cells have robust levels of hsa-mir-30c compared to non-metastatic MCF-7 cells; and that hsa-mir-30c promotes breast cancer cellular invasion through targeting of $\mathrm{NOV} / \mathrm{CCN} 3$, which we characterized as an inhibitor of invasion. We demonstrated the specificity of this pathway by showing: a) that only the canonical strand of hsa-mir-30c is detected and responsible for the invasive phenotype; and b) that hsamir-30c-NOV/CCN3-mediated invasiveness is completely independent of hsa-mir-30c targeting of RUNX2. Importantly, our cell-based experimental observations allow for mechanistic insight into the clinical observations of both hsa-mir-30c and NOV/CCN3, which suggests that the hsa-mir-30c-NOV pathway is an important target for future translational studies.

\section{Results}

hsa-mir-30c promotes the invasiveness of MDA-MB-231 breast cancer cells

Numerous miRNAs have been implicated in tumorigenesis, driving tumor progression, or promoting metastases; however, there are still many miRNAs that have yet to be characterized with respect to these oncogenic processes. Using cBioPortal $[15,16]$ to investigate the genomics and transcriptomics of TCGA breast cancer patients [12], we observed frequent amplifications in the genes MIR30C1 and MIR30C2, which encode the same mature miRNA, hsa-mir-30c, as well as many patients with significant (absolute value of Z-score $>=2.0$ ) changes in the levels of hsa-mir-30c (Figure 1A). Importantly, patients with alterations in copy number or expression of hsa-mir-30c have significantly poorer (log-rank $P$-value $<1.09 \mathrm{e}-03$ ) survival than their wild-type counterparts (Figure $1 \mathrm{~B}$ ). Because many of the observed alteration of hsa-mir-30c in patents were amplifications, increased expression levels, or both we sought to use cell-based models to characterize the functional impact of modulation of hsa-mir-30c.

In vitro, MCF-7 breast cancer cells have been observed to be less invasive than MDA-MB-231 cells [17]. Using Real Time qPCR, we observed statistically significantly higher levels of endogenous hsa-mir-30c in the more invasive breast cancer cell line MDA-MB-231 compared to the MCF7 cell line (Figure 1C). This finding suggests that increased expression of hsa-mir-30c is associated with more invasive breast cancer cells. To address the effect of hsa-mir-30c on the invasive potential of MDAMB-231 cells, MDA-MB-231 cells were transfected with either hsa-mir-30c or anti-mir-30c for $48 \mathrm{~h}$ and loaded the cells into the top of the transwell culture plates with or without a layer of Matrigel. Conditioned osteoblast 


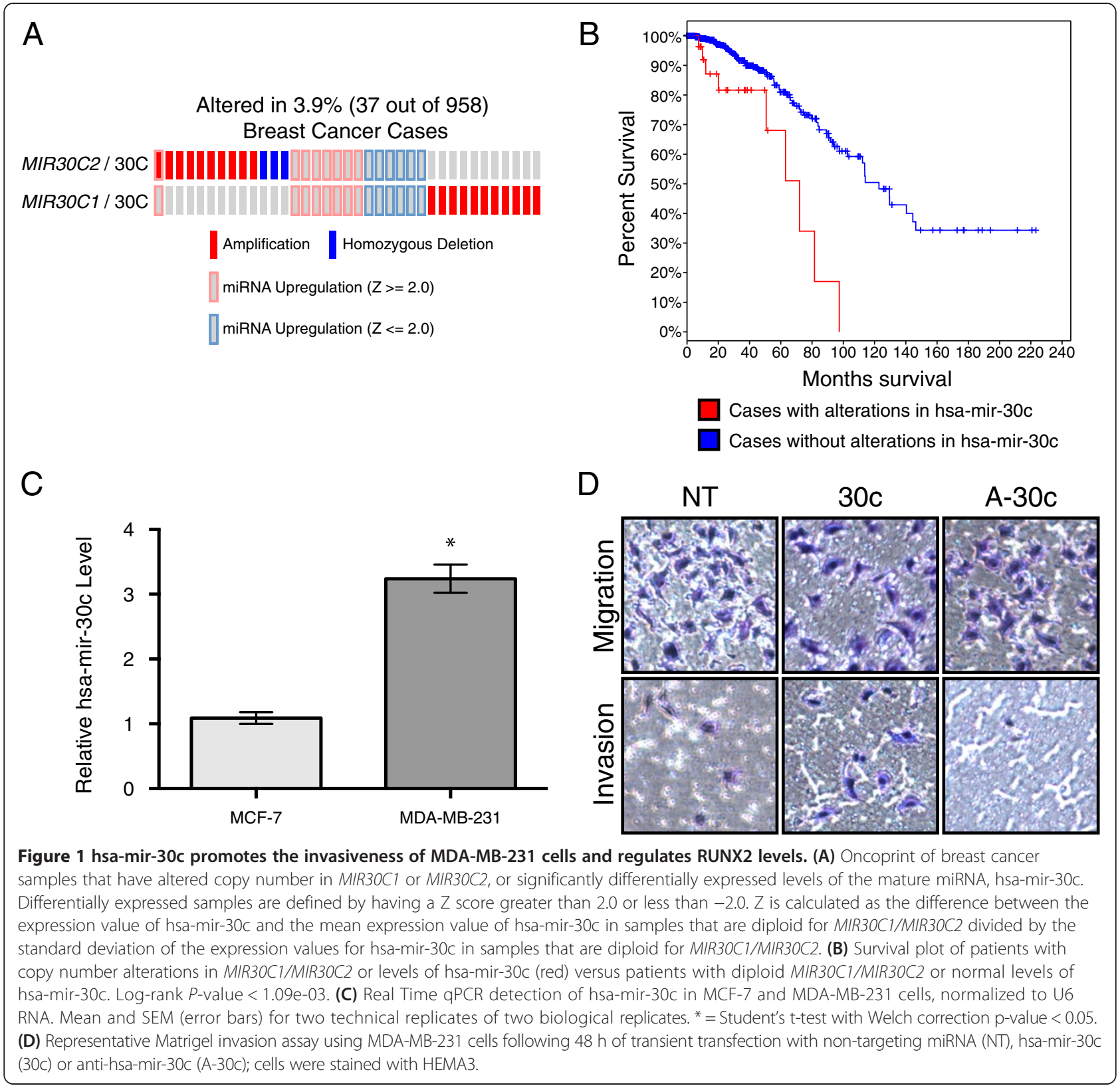

media was placed in the bottom well as a chemoattractant for the cells to mimic a bone environment (Figure 1D). Using this assay, we observed that more MDA-MB-231 cells transfected with hsa-mir-30c invaded through the Matrigel as compared to control transfected MDA-MB231 cells, which indicates that hsa-mir-30c promotes the invasiveness of MDA-MB-231 cells. When MDA-MB-231 cells were transfected with anti-mir-30c, we observed that less cells had invaded through the Matrigel as compared to control transfected MDA-MB-231 cells. Taken together, we conclude that hsa-mir-30c expression levels are linked with the invasive potential of MDA-MB-231 metastatic breast cancer cells.
The canonical 5-prime end of hsa-mir-30c, not the "star" or 3-prime end of hsa-mir-30c, promotes the invasiveness of MDA-MB-231 cells

During normal miRNA biogenesis, the stem-loop structure that is termed the pre-miRNA is cleaved and only one end of the longer pre-miRNA is integrated into the Dicer complex [18]. In the case of hsa-mir-30c, the 5'-end of the stem-loop is most commonly detected as the mature form of the miRNA [19]. When the "star" strand (or in the case of hsa-mir-30c the 3'-end of the stem-loop) is incorporated into the Dicer complex, a unique set of mRNAs is predicted to be targeted for translational repression of mRNA degradation. The phenomenon of 
alternate utilization of the non-canonical part of the pre-miRNA has been observed in leukemic cells [20]; therefore, we investigated the extent to which this kind of transformation may be occurring in MDA-MB-231 metastatic breast cancer cells.

To determine whether the hsa-mir-30c-mediated effect on the invasiveness of MDA-MB-231 cells was due to the canonical miRNA strand, we transiently transfected MDA-MB-231 cells with either hsa-mir-30c-5p (canonical) or hsa-mir-30c-3p (star) an measured the invasive properties of MDA-MB-231 cells using a Matrigel transwell assay. Transfection of MDA-MB-231 cells with hsa-mir-30c-3p resulted in a reduction of the number of cells that migrated through the transwells in the absence of Matrigel; however, transfection with hsa-mir-30c-3p did not significantly affect the number of cells that invaded through Matrigel (Figure 2A-C).

We examined endogenous expression of the canonical and star miRNA products of hsa-mir-30c miRNA biogenesis in the breast cancer cell lines (Figure 2D). Using primers specifically designed to detect either the 5'- or 3 '-form of hsa-mir-30c, we observed that the ratio of the endogenous levels of the 5 -form were several hundred fold higher than the 3'-form in both MDA-MB-231 and MCF-7 breast cancer cells and that the canonical form is 5 fold higher in the MDA-MB-231 compared to the MCF-7 cells. These results indicate that the phenomenon of "star"-strand miRNA activity of hsa-mir-30c does not

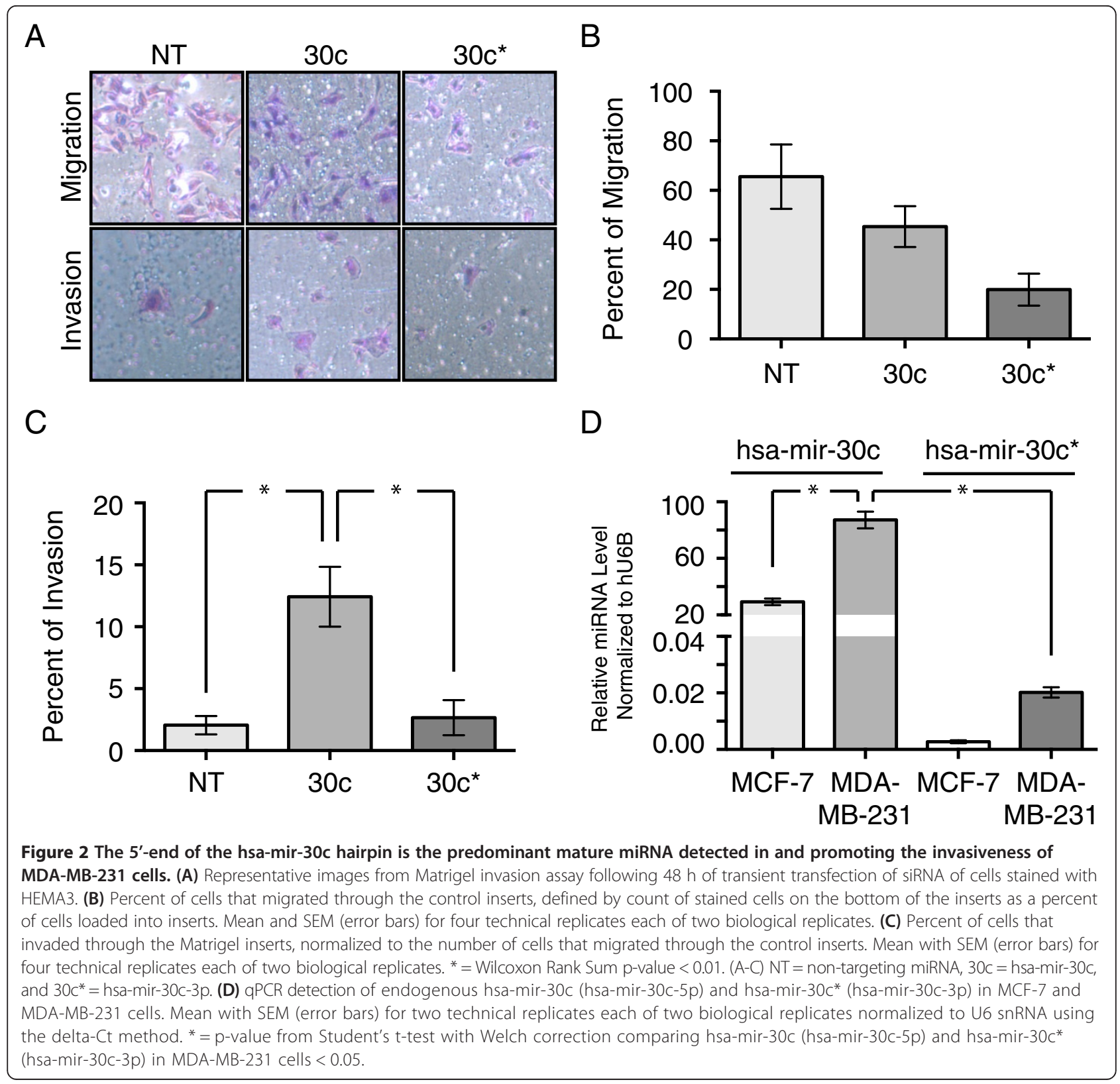


make a major contribution to the invasiveness of MDAMB-231 cells. Instead, only the canonical 5'-strand of hsamir-30c appears to be promoting the invasive phenotype of MDA-MB-231 metastatic breast cancer cells.

Screening via ontological terms and qPCR reveals NOV to be a target of hsa-mir-30c in MDA-MB-231 breast cancer cells

To identify potential targets of hsa-mir-30c participating in the invasive phenotype associated with hsa-mir-30c expression in MDA-MB-231 cells, we performed a screen in three steps: 1) generated a list of potential targets based on seed sequence targeting potential using the top 300 human mRNA targets from www.microrna. org [21]; 2) filtered the list based on known functions and ontological terms for mRNAs that code for proteins associated with invasion, adhesion, or migration, as well as mRNAs that code for transcription factors [22,23] (Table 1); 3) used qPCR to measure the relative mRNA levels of potential targets in MDA-MB-231 cells that had been transfected with either non-targeting miRNA or hsa-mir-30c. Using this screening approach, we observed that NOV mRNA was one of the two most down

Table 1 Genes chosen for qPCR screen

\begin{tabular}{|c|c|c|}
\hline \multicolumn{3}{|c|}{ Predicted hsa-mir-30c targets from microRNA.org } \\
\hline Gene symbol & mirSVR Score & References into function or ontology terms \\
\hline \multirow[t]{3}{*}{ TWF1 } & -3.02 & GO: Actin Binding \\
\hline & & Regulates actin filament turnover [31] \\
\hline & & $\begin{array}{l}\text { Promotes cellular motility through actin } \\
\text { regulation [32] }\end{array}$ \\
\hline \multirow[t]{3}{*}{ DYNLT3 } & -3.02 & GO: Cytoplasm, GO: Plasma Membrane \\
\hline & & Cytoplasmic dynein light chain protein that interacts with spindle checkpoint protein BUB3 [33] \\
\hline & & Functions as a nuclear matrix-associated transcription factor in a dynein-independent manner [34] \\
\hline \multirow[t]{3}{*}{ NEDD4 } & -2.47 & Modulates p-Smad1 signaling in response to both BMP-2 and TGF $\beta 1$ [35] \\
\hline & & Negatively regulates PTEN in an oncogenic fashion [36] \\
\hline & & Involved in the deposition of extracellular collagen [37] \\
\hline \multirow[t]{6}{*}{ PTPN3 } & -2.55 & Regulates EGF-mediated cell-cell contact [38] \\
\hline & & Regulates focal adhesion [39] \\
\hline & & Regulates Cadherin-mediated cell-cell contact [40] \\
\hline & & Regulates neural crest cell adhesion and motility [41] \\
\hline & & Controls hormone receptor signaling [42] \\
\hline & & Cooperates with vitamin D to promote breast cancer cell growth [43] \\
\hline \multirow[t]{4}{*}{ ADAM22 } & -2.44 & GO: Extracellular, GO: Metallopeptidase Activity \\
\hline & & $\begin{array}{l}\text { Metalloproteinase-like, disintegrin-like, cysteine-rich protein that is highly expressed in } \\
\text { brain tissue [44] }\end{array}$ \\
\hline & & Promotes cell adhesion and spreading [45] \\
\hline & & $\begin{array}{l}\text { Cooperates with SRC-1 in endocrine resistance of breast cancer cells; expression of ADAM22 } \\
\text { independently predicts poor survival in patients [46] }\end{array}$ \\
\hline \multirow[t]{9}{*}{ NOV } & -3.11 & Regulates actin cytoskeletal reorganization [28] \\
\hline & & Increases motility of chondrosarcoma cells [47] \\
\hline & & Promotes mineralization of osteoblasts [48] \\
\hline & & Transcriptionally activated by p53 [24] \\
\hline & & Downregulated in advanced melanomas [26] \\
\hline & & Downregulated in childhood adrenocortical tumors [25] \\
\hline & & $\begin{array}{l}\text { Significantly over-expressed in ER-positive breast cancer patients who relapsed after tamoxifen } \\
\text { treatment [49] }\end{array}$ \\
\hline & & Expression is negatively correlated with metastasis and progression in breast cancer [50] \\
\hline & & Promotes xenograph breast cancer bone-metastasis and osteolysis [27] \\
\hline
\end{tabular}


regulated in silico-identified target upon transfection of hsa-mir-30c (Figure 3A). We also examined several in silico-predicted targets related to cancer at the protein level and found these to be unaffected by the levels of hsa-mir-30c (Additional file 1: Figure S1). We focused on NOV, which is a member of the CCN family of matricellular signaling proteins, and has context-specific functions as an oncogene/tumor suppressor [24-28]. While CELSR3 had similar response trends to hsa-mir30c overexpression and is involved in cellular adhesion [29], we did not focus on CELSR3 because the expression levels were very low in MDA-MB-231 cells (data not shown) and CELSR3 was previously shown to not affect invasion in metastatic melanoma cells [30]. In parallel we also looked at in silico-predicted targets of hsa-mir-30c that have known functions in cancer and found that none of these predicted targets were affected by overexpression of hsa-mir-30c (Additional file 1: Figure S1). Using Western blotting to detect the levels of NOV protein, we also observed NOV protein to be reduced following transfection of MDA-MB-231 cells with hsa-mir-30c (Figure 3B). The observation that NOV mRNA was reduced upon transfection of hsamir-30c was highly reproducible in multiple biological replicates (Figure $3 \mathrm{C}$ ), consistent with the reduction in protein levels.

Comparing the sequence of hsa-mir-30c and the sequence of the NOV 3'-UTR, mirSVR [52] predicted

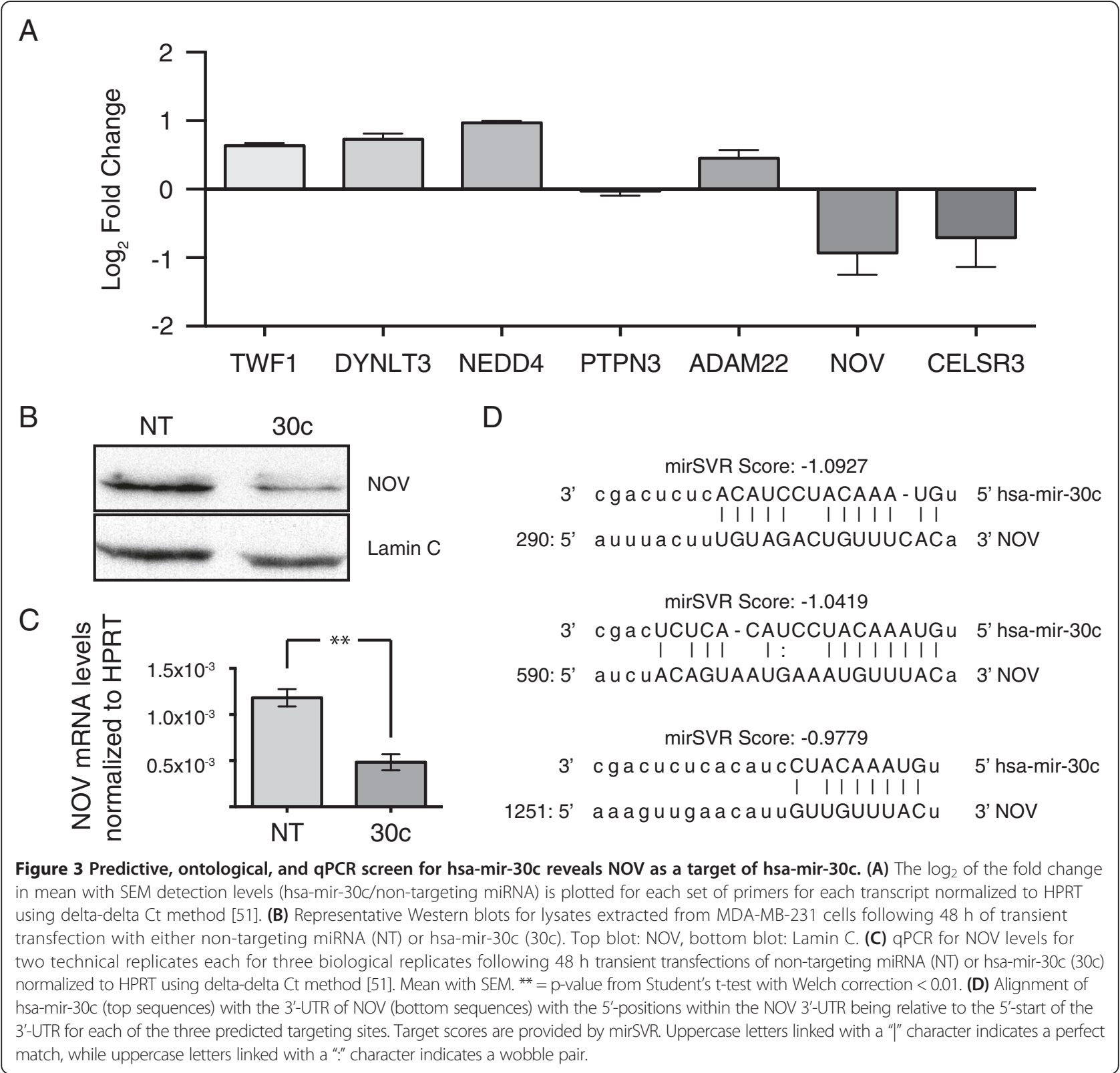


three potential binding sites for hsa-mir-30c (Figure 3D). Among the mir-30 family members, hsa-mir-30c appears to have the highest chance to target $\mathrm{NOV}$ as a unique site is predicted for hsa-mir-30c that is not shared by the other mir-30 family members (Additional file 2: Figure S2). Based on ontological terms associated with $\mathrm{NOV}$, and the observed reduction of NOV protein and mRNA levels in response to increased hsa-mir-30c levels, we suggest that NOV is involved in the regulation of MDA-MB-231 invasiveness.

\section{hsa-mir-30c regulation of NOV and invasion is independent of RUNX2}

Numerous factors have been implicated in the progression of breast cancer metastasis, and among these is RUNX2, a bone-lineage transcription factor that promotes the invasive phenotype of MDA-MB-231 cells
[53-55]. Because mmu-mir-30c is known to target Runx2 [13], we addressed whether there is regulatory cross talk between RUNX2, hsa-mir-30c, and NOV in breast cancer cells. RUNX2 levels were modulated in MDA-MB-231 by several approaches: overexpression, siRNA knockdown and by examining a functionally-deficient mutant form of Mus musculus Runx2 (R398A/Y428A), which inhibits the invasiveness of MDA-MB-231 [54-56] (Figure 4). We observed that constitutive overexpression of Runx2 or the R398A/Y428A-mutant form of Runx2 in MDA-MB-231 cell lines (see Methods) did not alter either the protein levels of NOV (Figure 4A) or the levels of hsa-mir-30c (Figure 4B), which were measured by Western blot and Real Time qPCR, respectively. Knockdown of RUNX2 via siRNA has also been previously shown to inhibit the invasiveness of MDA-MB-231 cells [53]. To further investigate whether RUNX2 can regulate the hsa-mir-30c/NOV

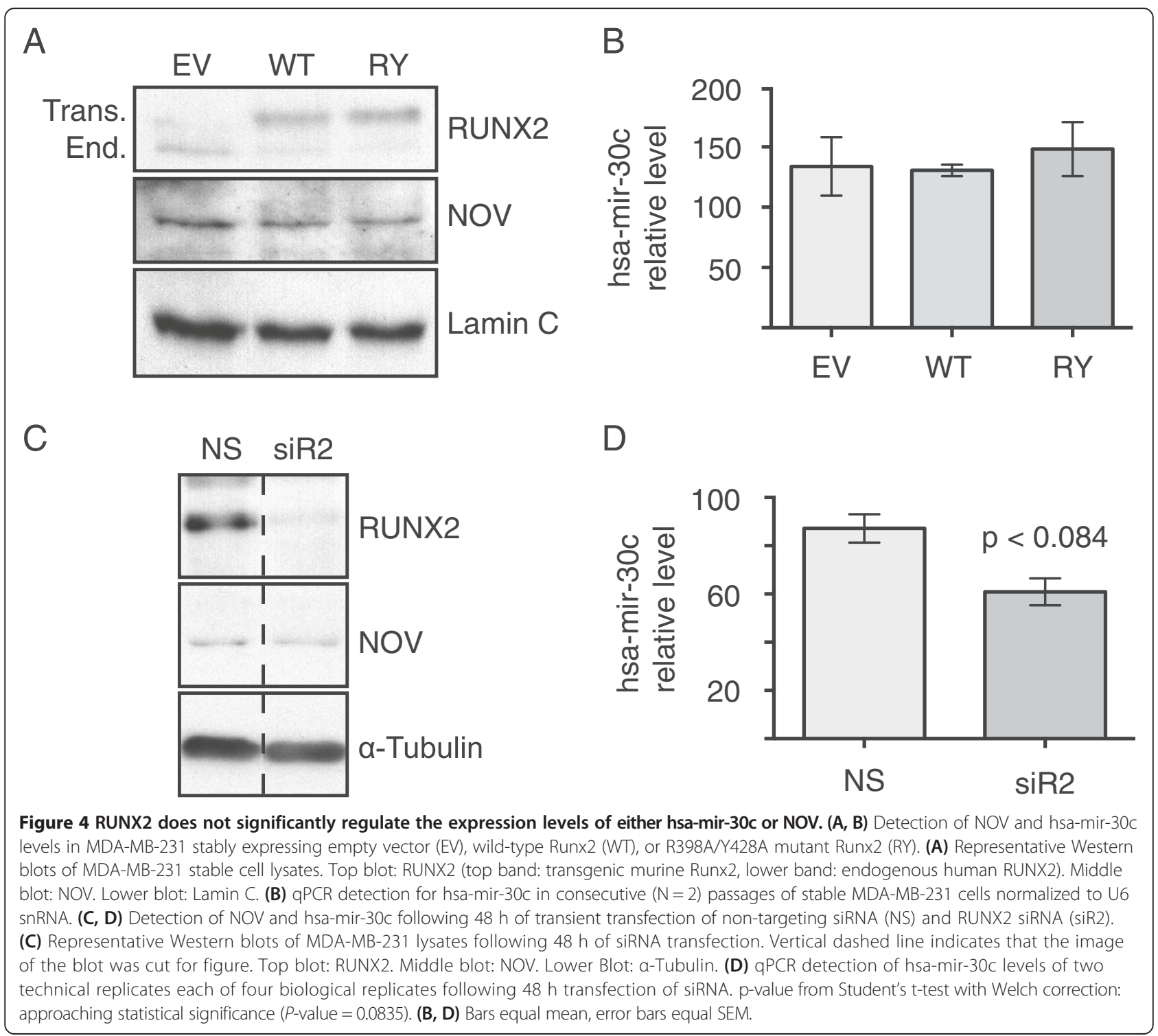


pathway, endogenous RUNX2 levels in MDA-MB-231 cells were reduced via siRNA. We observed that NOV protein levels were not affected by RUNX2 knockdown (Figure 4C), and that hsa-mir-30c levels, while slightly reduced, were not statistically significantly changed by RUNX2 siRNA (Figure 4D). These results demonstrate that the hsa-mir-30c/NOV-mediated regulation of the invasiveness of MDA-MB-231 cells is occurring through a RUNX2-independent pathway.

NOV inhibits the invasiveness of MDA-MB-231 cells

To determine the extent to which hsa-mir-30c targeting and reduction of NOV was involved in the increased invasion of MDA-MB-231 cells following transfection of hsa-mir-30c, we transfected MDA-MB-231 cells with
NOV-specific siRNA to reduce NOV protein levels without directly affecting other targets of hsa-mir-30c (Figure 5A). We postulate if hsa-mir-30c-mediated downregulation of NOV levels is a key contributor to the invasiveness of MDA-MB-231 cells, we should therefore observe that siRNA-mediated knockdown of NOV results in an invasive phenotype similar to overexpression of hsa-mir-30c. The levels of NOV were significantly reduced by the siRNA (Figure 5A), and using Matrigel invasion assay, we observed an increase in the number of MDA-MB-231 that invaded through the Matrigel (Figure 5B-D). MDA-MB-231 cells lacking NOV were significantly more invasive (Figure $5 \mathrm{D}$ ), yet were less migratory (Figure $5 \mathrm{C}$ ). While it is often observed that trends in invasion and migration are positively correlated,
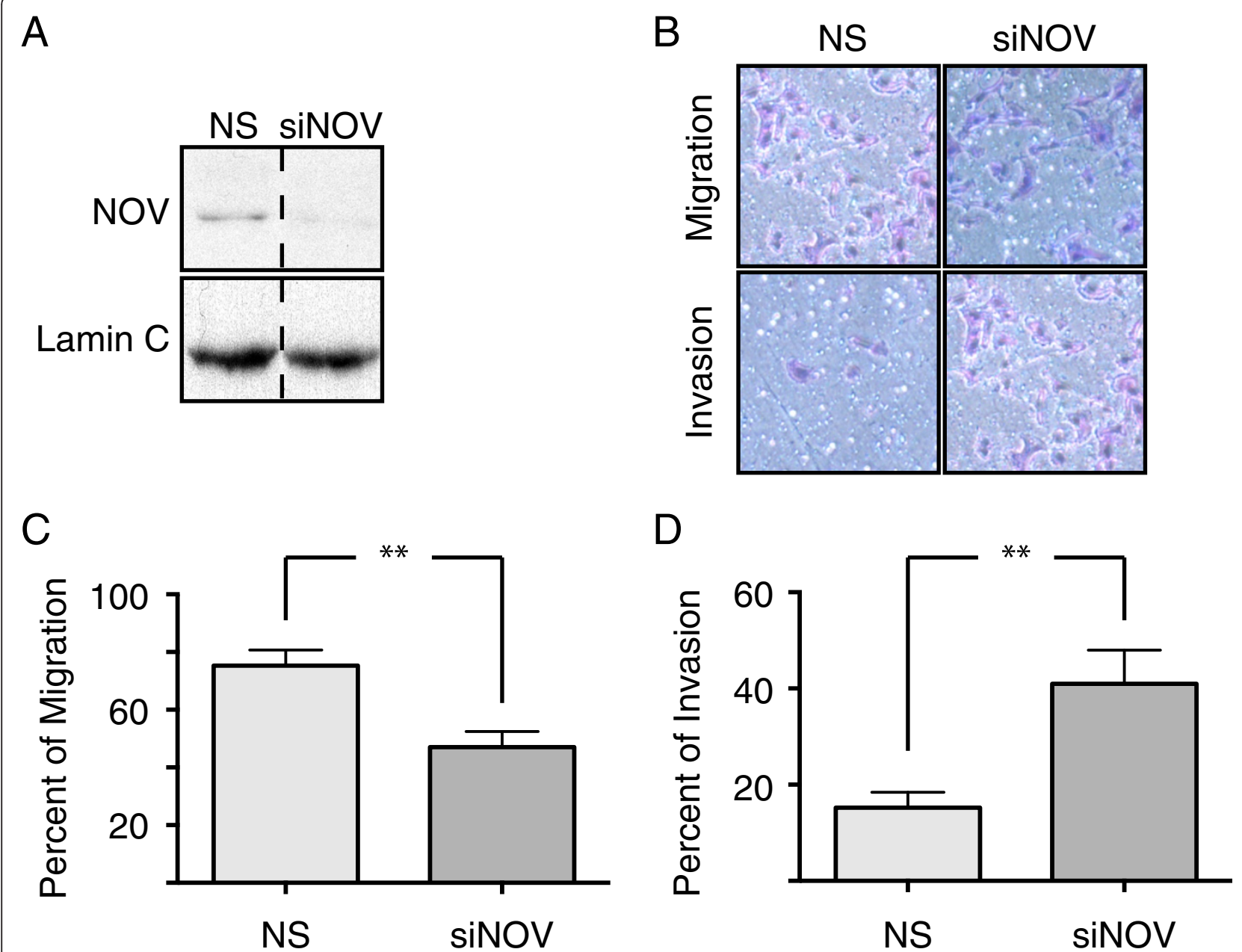

Figure 5 NOV inhibits the invasiveness of MDA-MB-231 cells. (A) Representative Western blot for NOV (upper blot) and tubulin (lower blot) $48 \mathrm{~h}$ post-transfection with siRNA. Vertical dashed line indicates where image of gel was cut for figure. (B) Representative image of HEMA-3 stained cells, which migrated through either the control inserts (upper row) or Matrigel inserts (lower row) after $48 \mathrm{~h}$ of transfection with siRNA. (C) Quantification of 4 technical replicates of 2 biological replicates measuring the percent of cells that migrated through the control inserts (100\% being the number of cells loaded into the inserts). (D) Quantification of 4 technical replicates of 2 biological replicates measuring the percent of cells that invaded through the Matrigel normalized by the number of cells migrated through the control inserts. (A-D) NS = Non-silencing siRNA, siNOV = NOV siRNA. (C, D) Bars equal mean, error bars equal SEM. ${ }^{* *}=$ Wilcoxon Rank Sum p-value $<0.01$. 
we observed less migration coupled with increased invasion in the absence of NOV. These results suggest that in MDA-MB-231 cells, NOV has distinct regulatory roles for the pathways governing invasion and migration. Taken together, our findings support the conclusion that the targeting of NOV by hsa-mir-30c is an important factor in the invasive phenotype evidenced by the MDA-MB-231 cells as illustrated in Figure 6.

\section{Discussion}

Here we identify a novel pathway by which hsa-mir-30c promotes the invasiveness of the MDA-MB-231 cell line through targeting of NOV. The specificity of NOV's involvement in the invasive phenotype observed by several experimental approaches including the knockdown by an siRNA targeting NOV, which resulted in significant increases in the invasiveness of MDA-MB-231, consistent with the high levels of hsa-mir-30c, and NOV cellular protein levels in these cells. These results demonstrate a novel pathway by which a miRNA (hsa-mir-30c) promotes the invasive phenotype of metastatic breast cancer cells.

The large mir-30 family shares a conserved seed sequence. However, our in silico research suggests that seed sequence differences may give rise to selectivity in targeting aggressive compared to modestly invading cells among mir-30 members. It is appreciated from the literature that the miR-30 family has numerous targets, and others have been identified in breast [57-59] and

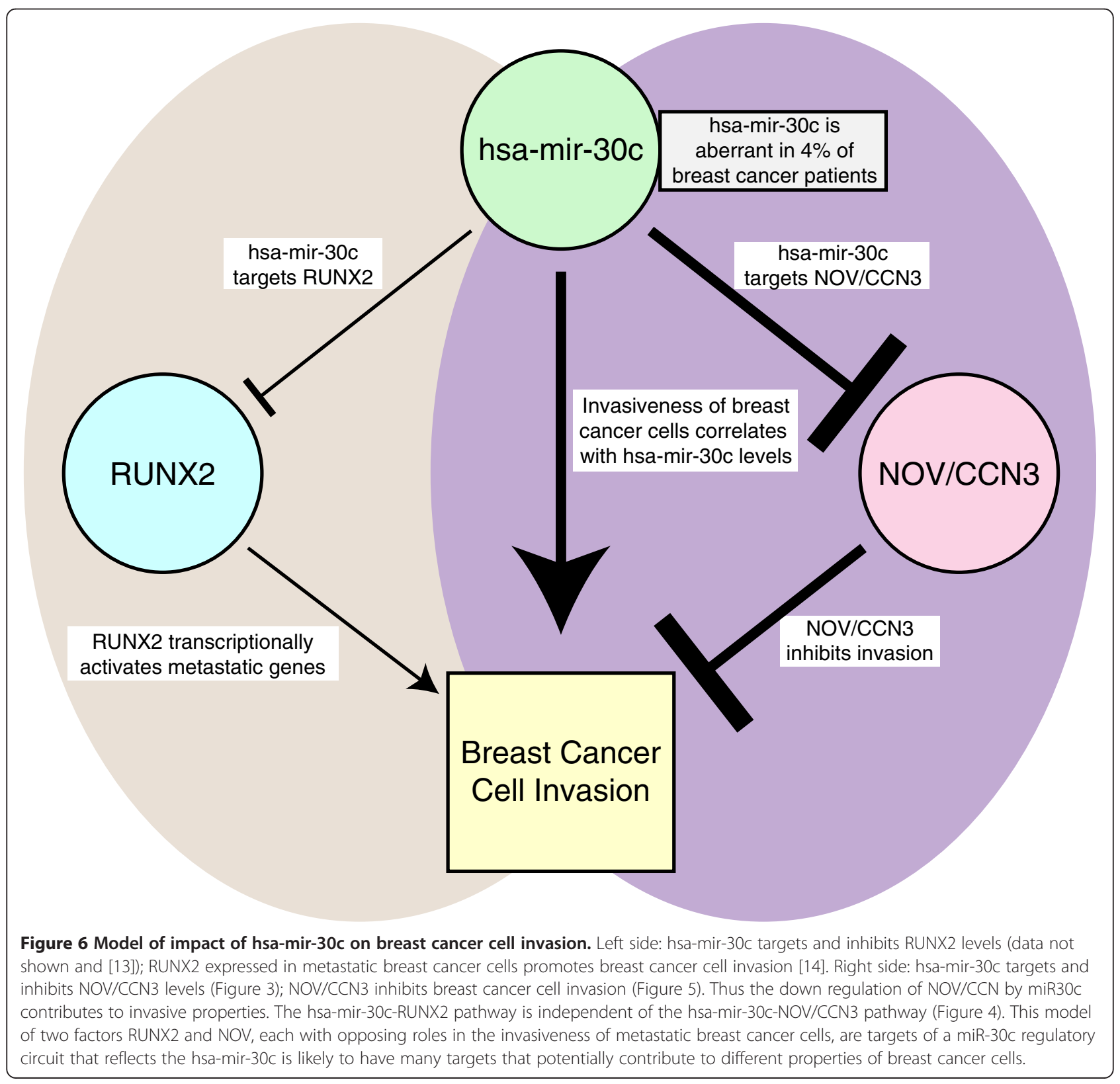


other cancers [30,60-64]. For example, a recent study showed that has-mir-30a marker targets the 3'-UTR of Vimentin (VIM) which was observed to cause reductions in both VIM protein levels and invasiveness of MDAMB-231 cells [63], and here we demonstrate that miR$30 \mathrm{c}$ also promotes cellular invasion by targeting NOV. It is also quite interesting that these mir-30 miRNAs appear on many chromosomes rather than co-regulated in a cluster, and are involved in the regulation of a myriad of pathways such as tumor suppression (p53) [63], apoptosis (BCL) [64], and epithelial to mesenchymal transition (VIM) [59]. Individual members of the mir-30 family have been implicated in both tumor suppression and oncogenesis; it is therefore difficult to define the family as a "tumor suppressive" or "oncogenic". This ambiguity makes studying the functions of the mir30 family members on a case-by-case basis critical for understanding the basis of post-transcriptional molecular mechanisms of disease. The relative levels of the mir-30 family members and their temporal expression may play a critical role in disease progression.

Also, to be considered is the context in which our experiments were conducted. We investigated the functions of hsa-mir-30c in MCF-7, a less invasive breast cancer cell line and the more invasive MDA-MB-231 cells, which is a cell model of advanced metastatic breast cancer [65]. We find a positive in correlation in levels of hsa-mir-30c and invasion properties in vitro assays and high expression of hsa-mir-30c has been observed in MDA-MB-231cells, as well as in other cellular models of breast cancer. However detection of hsa-mir-30c did not appear to be predictive of breast cancer subtypes [66]. Our cell-based observations are similar to observations made in in vivo studies of miRNA expression patterns in breast cancer patient samples in which hsa-mir-30c expression was not significantly associated with any clinical or pathological features [12,67-70]. However, elevated expression of hsa-mir-30c was observed to be significantly associated with estrogen receptor (ER) positive breast cancers that were beneficially responsive to tamoxifen treatment [58]. In a separate study, ER-positive breast cancer patients who relapsed after tamoxifen treatment had significantly increased levels of NOV [49], which further underscores the inverse relationship between NOV and hsa-mir-30c in breast cancer, as well as in our observations of low hsa-mir-30c in the ER positive cell line (MCF-7) and higher levels in the MDA-MB-231 cells which are ER negative.. Thus, we have observed that hsa-mir-30c was important for the invasive properties which is discordant with the in vivo observations that hsa-mir-30c expression was not positively associated with metastatic disease, but rather, with positive outcome in response to hormone therapy. We therefore suggest that the cohort of potential mRNA targets available to hsa-mir-30c in patients may be quite different from those in MDAMB-231 cells, which could explain the differences between in vivo tumors with a heterogenous tumor cell population and individual cell lines. The significance of our findings is that there are likely to be tumor cells during progression of breast cancer in vivo that could benefit from targeted hsa-mir-30c or NOV therapy in reducing invasion and later stage metastasis.

We have demonstrated that the functional consequence of increased invasiveness of MDA-MB-231 cells following the reduction of NOV through either hsa-mir30c or NOV-siRNA is directly sensitive to NOV levels. NOV appears to play a context-sensitive role in oncogenesis/tumor suppression [71]. In several cancers that develop from mesenchymal tissues, NOV has been shown to promote tumor growth and metastasis [72-74]. However, in the context of brain cancer, NOV appears to inhibit disease progression [53,75-77], but in the context of alveolar rhabdmyosarcoma NOV/CCN3 levels are increased and contribute to survival of oppressive behaviors of the cancerous cells promotes motility. While there are conflicting observations of NOV functions in breast cancer cell lines [28,49], NOV protein levels in human tissue samples of breast cancer were observed to be negatively correlated with late-stage and metastatic disease [50]. These histological observations suggest that in breast cancer, NOV functions to inhibit disease progression.

\section{Conclusions}

We have demonstrated that hsa-mir-30c-mediated inhibition of NOV levels promotes the invasive phenotype of MDA-MB-231 cells. We find that lower levels of the canonical hsa-mir-30c are correlated with modest invasion of MCF-7 compared to the aggressive invasion of MDA-MD-231 cells, which express high levels of hsamir-30c. The mechanism we have uncovered related to hsa-mir-30c is that that the functional consequence of increased invasiveness of MDA-MB-231 cells following the targeting and reduction of NOV through either hsamir-30c or NOV-siRNA and that the invasive properties of the metastatic breast cancer cell line MDA-MB-231i are directly sensitive to NOV levels. NOV/CCN3 expression in patients is known to inversely correlate with advanced breast cancer and metastasis. Thus, a key function of NOV is the inhibition of the invasiveness of metastatic breast cancer cells.

\section{Methods \\ Cell Properties \\ Cell lines}

MCF-7 cells were grown in DMEM in media and MDAMD-231 cells in alpha MEM and maintained as previously described [53]. These cells have been maintained 
in our laboratory and used in seven publications since 2005. In 2012 the cells were revalidated by satellite phenotyping. These cell lines were grown and maintained as previously described [53]. Constructs and stable cell lines were generated as previously described [56]. MDA-MB231 cells which were lentivirus-transduced stable cell lines to express either empty vector, wild-type Mus musculus Runx2 a subnuclear-targeting-deficient mutant form of Mus musculus Runx2 (R398A/Y428A), which inhibits the invasiveness of MDA-MB-231 [54-56] were used in these studies.

\section{RNA isolation}

RNA was isolated using Qiagen miRNAeasy Mini Kit (217004) following the manufacturer's recommended protocol with optional in-column DNAse I digestion of genomic DNA (Qiagen RNase-Free DNase Set 79254).

\section{miRNA amplification and detection}

Complimentary miRNA-specific cDNA was amplified and detected using Applied Biosystems TaqMan MicroRNA Assays for hsa-mir-30c (\#4427975) hsa-mir-30c-2* (\#4427975) and RNU6B (\#4427975).

\section{cDNA amplification and detection}

cDNA was amplified from equal quantities of total cellular RNA for each treatment or cell line. cDNA was amplified using the Invitrogen SuperScript First-Strand Synthesis System for RT-PCR (\#11904-018) according to the manufacturer's protocol. Reactions were volumetrically diluted, and reaction products were used as templates for Real Time qPCR using Bio-Rad iQ SYBR Green Supermix (\#170-8880).

\section{CDNA qPCR primers}

Real Time qPCR primers were designed using FoxPrimer (www.foxprimer.org) and validated for efficiency by standard curve using cDNA amplified from untreated MDAMB-231 cells.

\section{Protein isolation and Western blotting}

Cells grown on tissue culture plates were placed directly on ice, and washed twice with PBS supplemented with Roche cOmplete, EDTA-free Protease Inhibitor Cocktail (\#11873580001) and $25 \mu \mathrm{M}$ MG132 (Calbiochem (EMD Millipore) CAS 133407-82-6). Cells were scraped into screw-top microcentrifuge tubes, gently spun down to pellet cells and excess PBS was aspirated and discarded. Cells were snap-frozen in liquid nitrogen. Protein lysates were prepared by the addition of RIPA buffer $(50 \mathrm{mM}$ Tris $\mathrm{pH} 7.4,150 \mathrm{mM} \mathrm{NaCl}, 2 \mathrm{mM}$ EDTA, $1 \% \mathrm{v} / \mathrm{v}$ NP-40, $0.1 \%$ w/v SDS, $1 \times$ Roche cOmplete, EDTA-free Protease Inhibitor Cocktail and $25 \mu \mathrm{M}$ MG132) and placing tubes on a $100{ }^{\circ} \mathrm{C}$ heat block for $10 \mathrm{~min}$. Protein lysates were quantified using Pierce BCA Protein Assay Kit (\#23225) according to manufacturer's instructions. Fifty $\mu \mathrm{g}$ protein per sample was loaded onto an SDS-PAGE gel. SDS-PAGE was performed as described [53]. Briefly, lysates were run through an $8.5 \%$ acrylamide gel, and then transferred to a PVDF Transfer Membrane (Thermo Scientific \#88518).

Membranes were blocked with 5\% (w/v) milk (BioRad \#170-6404XTU) in PBS and then subjected to immunodetection using the following primary antibodies and dilution factors in $1 \%(\mathrm{w} / \mathrm{v})$ milk in PBS: NOV (Santa Cruz Biotechnology H-71 sc-50304 1:1000), Lamin A/ C (Santa Cruz Biotechnology N-18 sc-6215 1:5000), $\alpha-$ Tubulin (Santa Cruz Biotechnology H-300 sc-5546 1:2000), RUNX2 (mouse hybridoma clone 8 G5 1:1000) [53], FOXG1 (Santa Cruz Biotechnology N-15 sc-1858), SATB2 (Santa Cruz Biotechnology H-118 sc-98677), SMAD2 (Santa Cruz Biotechnology S-20 sc-6200), MTSS1 (Santa Cruz M7-P3A7 sc-101390), WWP1 (Santa Cruz Biotechnology N-20 sc-11892), RUNX1 (Active Motif \#39000), Cdk2 (Santa Cruz Biotechnology M2 sc-163). Secondary antibodies used were from Santa Cruz Biotechnology and were diluted 1:5000 in 1\% (w/v) milk in PBS: donkey anti-goat IgG-HRP (sc-2020), goat anti-mouse IgG-HRP (sc-2005), and goat anti-rabbit IgGHRP (sc-2004). After incubation with primary and secondary antibodies, the membranes were washed three times for 30 min each with $0.1 \%(\mathrm{v} / \mathrm{v})$ Tween-20 in PBS. HRP reaction was achieved by one minute incubation with Perkin Elmer Western Lightning ECL (NEL102001EA). Membranes were exposed to Kodak BioMax Light File for Chemiluminescent Imaging (\#868-9358) in serial exposure times to empirically determine the exposure time at which the signal was most linear.

\section{Matrigel invasion and migration assays}

Proliferating MDA-MB-231 cells were trypsinized and counted using Cellometer Auto T4 Cell Counter. A cell suspension of 100,000 cells $/ \mathrm{mL}$ in growth medium was prepared and $100 \mu \mathrm{L}$ of the suspension was loaded into each BD Matrigel 24-well $8.0 \mu \mathrm{m}$ PET Membrane Invasion Chamber (\#354483). Matrigel coated plates, and control insert plates had $500 \mu \mathrm{L}$ NIH3T3-conditioned medium loaded in the bottom as the chemoattractant. Plates and chemoattractant medium were incubated at $37{ }^{\circ} \mathrm{C}$ for $3-4 \mathrm{~h}$ prior to loading MDA-MB-231 cells. Cells were incubated for $16 \mathrm{~h}$ at $37^{\circ} \mathrm{C}$ in $5 \% \mathrm{CO}_{2}$ and then fixed and stained using the Fisher HealthCare PROTOCOL Hema 3 Manual Staining System (\#22-122911) according to the manufacturer's instructions. Cotton swabs were used to eliminate cells which did not migrate/ invade as well as Matrigel. Cells were counted using an inverted light microscope. To control for proliferation effects, rates of cellular invasion through Matrigel were 
normalized by rates of cellular migration through control plastic-only insert wells.

\section{Transient transfection}

Proliferating MDA-MB-231 cells were transfected with 50nM of siRNA/miRNA using Oligofectamine (Invitrogen \#12252-011) according to the Oligofectamine protocol.

\section{siRNAs}

Dharmacon SMARTpool: ON-TARGETplus RUNX2 siRNA (L-012665-00-0005); Dharmacon SMARTpool: ONTARGETplus NOV siRNA (L-010527-00-0005); Dharmacon ON-TARGETplus Non-targeting Pool (D-001810-10-05).

\section{miRNAs and anti-miRNAs}

Dharmacon miRIDIAN microRNA hsa-mir-30c-1 mimic (C-300542-03-0005); Dharmacon miRIDIAN microRNA hsa-mir-30c-1* mimic (C-301199-01-0005); Dharmacon miRIDIAN microRNA hsa-mir-30c-1 haripin inhibitor (IH-300542-07-0005); Dharmacon miRIDIAN microRNA Mimic Negative Control \#1 (CN-001000-01-05); Dharmacon miRIDIAN microRNA Hairpin Inhibitor Negative Control \#1 (IN-001005-01-05).

\section{Screen for hsa-mir-30c targets}

The top 300 targets of hsa-mir-30c based on mirSVR were downloaded from www.microrna.org in January 2011. Gene symbols were used to access gene ontology (GO) terms from DAVID (http://david.abcc.ncifcrf.gov) and gene reference into function (GeneRIF) from NCBI (http://www.ncbi.nlm.nih.gov/gene/about-generif). Genes whose GO terms or GeneRIFs were associated with invasion, migration, extracellular matrix, or transcription factors were selected and qPCR primers were designed. After $48 \mathrm{~h}$ of transfection, RNA was isolated, cDNA was amplified and Real Time qPCR was carried out to detect the relative levels of mRNAs following transfection with hsa-mir-30c.

\section{Additional files}

Additional file 1: Figure S1. Western blot screening of potential cancer-related targets of hsa-mir-30c. (A and B) Western blots showing protein levels of FOXG1, SATB2, SMAD2, MTSS1, WWP1, RUNX1, and CDK2 in whole cell lysates from MDA-MB-231 cells following 36 hours of transient transfection with either mock (M), non-targeting miRNA (NT), or hsa-mir-30c (30c).

Additional file 2: Figure S2. Alignment of mir-30 family members on the NOV $3^{\prime}-U T R$. For each of the predicted sites of targeting by hsa-mir-30c on the NOV $3^{\prime}-U T R(A-C)$, if an alignment is possible, the alignment of each mir-30 member is presented. Alignment of hsa-mir-30 family members (top sequences) with the $3^{\prime}$-UTR of NOV (bottom sequences); the 5'-positions within the NOV 3'-UTR are relative to the 5'-start of the 3'-UTR for each of the three predicted targeting sites. Target scores are provided by mirSVR. Uppercase letters linked with a "|" character indicates a perfect match, while uppercase letters linked with a ":". indicate a wobble pair.

\section{Abbreviations}

3'-UTR: Three prime untranslated region; ADAM22: Homo sapiens ADAM metallopeptidase domain 22; BCL: Homo sapiens B-cell lymphoma 2; BMP-2: Homo sapiens bone morphogenetic protein 2; BUB3: Homo sapiens BUB3 mitotic checkpoint protein; CCN: Family of extracellular matrix proteins, which includes NOV; CELSR3: Homo sapiens cadherin EGF LAG seven-pass G-type receptor 3; DYNLT3: Homo sapiens dynein, light chain, Tctex-type 3; EGF: Homo sapiens epidermal growth factor; ER: Homo sapiens estrogen receptor alpha; GO: Gene ontology; HPRT: Homo sapiens hypoxanthine-guanine phosphoribosyltransferase; MCF-7: Poorly invasive, malignant breast cancer cell line; MDA-MB-231: Metastatic breast cancer cell line; NEDD4: Homo sapiens neural precursor cell expressed, developmentally down-regulated 4, E3 ubiquitin protein ligase; NOV/CCN3: Homo sapiens nephroblastoma overexpressed; PTEN: Homo sapiens phosphatase and tensin homolog; PTPN3: Homo sapiens protein tyrosine phosphatase, non-receptor type 3; R398A: Arginine 398 mutated to alanine; RNA-seq: Ribonucleic acid sequencing; RUNX2: Homo sapiens runt-related transcription factor 2; Runx2: Mus musculus runt-related transcription factor 2; SRC-1: Homo sapiens V-Src avian sarcoma (Schmidt-Ruppin A-2) viral oncogene homolog; TBF 1 1: Homo sapiens transforming growth factor, beta 1; TWF1: Homo sapiens twinfilin actin-binding protein 1; VIM: Homo sapiens vimentin; Y428A: Tyrosine 428 mutated to alanine; hsa-mir-30c: Homo sapiens miRNA 30c; hsa-mir-30c-3p: Alternative, 3'-form of hsa-mir-30c; hsa-mir-30c-5p: Canonical, 5'-form of hsa-mir-30c; mRNA: Messenger ribonucleic acid; metasta-miR: An miRNA that promotes cancer cell metastasis; miRNA: Small non-coding ribonucleic acid; mirSVR: A score derived from a machine learning method for ranking miRNA target sites; mmu-mir-30c: Mus musculus miRNA 30c; onco-miR: An miRNA that has oncogenic functions; p-Smad1: Homo sapiens SMAD family member 1, phosphorylated; p53: Homo sapiens tumor suppressor protein 53; pre-miRNA: immature transcript of an miRNA; qPCR: Quantitative polymerase chain reaction; siRNA: Short interfering ribonucleic acid.

\section{Competing interests}

The authors declare that they have no competing interests.

\section{Authors' contributions}

qPCR for miRNAs performed by JRD and HT. qPCR for RUNX2 and NOV performed and analyzed by JRD. siRNA and miRNA transfections performed by JRD. Invasion assays performed by JRD and HT. Western blotting performed by JRD. MDA-MB-231 cells stably overexpressing Runx2 and Runx2-RY engineered by DH. Initial cancer-centric screens for hsa-mir-30c targets in MDA-MB-231 cells performed by YH and JP. Ontological and GPCR screen was designed and executed by JRD. Study was executed under the guidance of JBL, AJVW, JLS, GSS, and JP, who contributed to the writing of this manuscript. All authors read and approved the final manuscript.

\section{Acknowledgements}

The authors acknowledge financial support from the National Institutes of Health (National Cancer Institute P01 CA082834, National Institute of Dental and Craniofacial Research R37 DE012528, National Institute of Arthritis and Musculoskeletal and Skin Diseases R01 AR039588).

\section{Author details}

${ }^{1}$ Department of Cell and Developmental Biology, University of Massachusetts Medical School, 55 Lake Ave, North, Worcester, MA 01655, USA. ²Current address: Center for Computational Molecular Biology, Department of Molecular Biology, Cell Biology, and Biochemistry, and Department of Computer Science, Brown University, 115 Waterman Street, Providence, RL 02912, USA. ${ }^{3}$ Current address: Heisenberg-Group for Molecular Skeletal Biology, Department of Trauma, Hand, and Reconstructive Surgery, University Medical Center Hamburg-Eppendorf, Hamburg, Germany. ${ }^{4}$ Current address: Department of Biochemistry and Vermont Cancer Center, University of Vermont College of Medicine, 89 Beaumont Avenue, Burlington, VT 05405-0068, USA. ${ }^{5}$ Current address: Departments of Orthopedic Surgery and Biochemistry \& Molecular Biology, Mayo Clinic, 200 First Street SW, Medical Sciences Building 3-69, Rochester, MN 55905, USA. ${ }^{6}$ Current address: Department of Anatomy and Cell Biology, Rush University Medical Center, Armour Academic Center, 600 S, Paulina Street, Suite 507, Chicago, IL 60612, USA. 
Received: 19 March 2014 Accepted: 19 July 2014

Published: 2 August 2014

\section{References}

1. Talmadge JE, Fidler IJ: AACR centennial series: the biology of cancer metastasis: historical perspective. Cancer Res 2010, 70(14):5649-5669.

2. Gupta GP, Massague J: Cancer metastasis: building a framework. Cell 2006, 127(4):679-695.

3. Hanahan D, Weinberg RA: Hallmarks of cancer: the next generation. Cell 2011, 144(5):646-674.

4. Wang Y, Klijn JG, Zhang Y, Sieuwerts AM, Look MP, Yang F, Talantov D, Timmermans M, Meijer-van Gelder ME, Yu J, Jatkoe T, Berns EM, Atkins D, Foekens JA: Gene-expression profiles to predict distant metastasis of lymphnode-negative primary breast cancer. Lancet 2005, 365(9460):671-679.

5. Ebert MS, Sharp PA: Roles for microRNAs in conferring robustness to biological processes. Cell 2012, 149(3):515-524.

6. Croce CM: Causes and consequences of microRNA dysregulation in cancer. Nat Rev Genet 2009, 10(10):704-714.

7. O'Day E, Lal A: MicroRNAs and their target gene networks in breast cancer. Breast Cancer Res 2010, 12(2):201.

8. Hurst DR, Edmonds MD, Welch DR: Metastamir: the field of metastasis-regulatory microRNA is spreading. Cancer Res 2009, 69(19):7495-7498.

9. Pencheva N, Tavazoie SF: Control of metastatic progression by microRNA regulatory networks. Nat Cell Biol 2013, 15(6):546-554.

10. Valastyan S: Roles of microRNAs and other non-coding RNAs in breast cancer metastasis. J Mammary Gland Biol Neoplasia 2012, 17(1):23-32.

11. Ell B, Mercatali L, Ibrahim T, Campbell N, Schwarzenbach H, Pantel K, Amadori D, Kang Y: Tumor-induced osteoclast miRNA changes as regulators and biomarkers of osteolytic bone metastasis. Cancer Cell 2013, 24(4):542-556.

12. The Cancer Genome Atlas Network: Comprehensive molecular portraits of human breast tumours. Nature 2012, 490(7418):61-70.

13. Zhang Y, Xie RL, Croce CM, Stein JL, Lian JB, van Wijnen AJ, Stein GS: A program of microRNAs controls osteogenic lineage progression by targeting transcription factor Runx2. Proc Natl Acad Sci U S A 2011, 108(24):9863-9868.

14. Pratap J, Lian JB, Stein GS: Metastatic bone disease: role of transcription factors and future targets. Bone 2011, 48(1):30-36.

15. Cerami E, Gao J, Dogrusoz U, Gross BE, Sumer SO, Aksoy BA, Jacobsen A, Byrne CJ, Heuer ML, Larsson E, Antipin Y, Reva B, Goldberg AP, Sander C, Schultz N: The cBio cancer genomics portal: an open platform for exploring multidimensional cancer genomics data. Canc Discov 2012, 2(5):401-404.

16. Gao J, Aksoy BA, Dogrusoz U, Dresdner G, Gross B, Sumer SO, Sun Y, Jacobsen A, Sinha R, Larsson E, Cerami E, Sander C, Schultz N: Integrative analysis of complex cancer genomics and clinical profiles using the cBioPortal. Sci Signal 2013, 6(269):11

17. Morini M, Mottolese M, Ferrari N, Ghiorzo F, Buglioni S, Mortarini R, Noonan DM, Natali PG, Albini A: The alpha 3 beta 1 integrin is associated with mammary carcinoma cell metastasis, invasion, and gelatinase B (MMP-9) activity. Int J Cancer 2000, 87(3):336-342.

18. Kim VN: MicroRNA biogenesis: coordinated cropping and dicing. Nat Rev Mol Cell Biol 2005, 6(5):376-385.

19. Griffiths-Jones S, Grocock RJ, van Dongen S, Bateman A, Enright AJ: miRBase: microRNA sequences, targets and gene nomenclature. Nucleic Acids Res 2006, 34(Database issue):D140-D144.

20. Kuchenbauer F, Mah SM, Heuser M, McPherson A, Ruschmann J, Rouhi A, Berg T, Bullinger L, Argiropoulos B, Morin RD, Lai D, Starczynowski DT, Karsan A, Eaves CJ, Watahiki A, Wang Y, Aparicio SA, Ganser A, Krauter J, Döhner H, Döhner K, Marra MA, Camargo FD, Palmqvist L, Buske C, Humphries RK: Comprehensive analysis of mammalian miRNA* species and their role in myeloid cells. Blood 2011, 118(12):3350-3358.

21. Betel D, Wilson M, Gabow A, Marks DS, Sander C: The microRNA.org resource: targets and expression. Nucleic Acids Res 2008, 36(Database issue):D149-D153.

22. Pruitt KD, Tatusova T, Klimke W, Maglott DR: NCBI Reference Sequences: current status, policy and new initiatives. Nucleic Acids Res 2009, 37(Database issue):D32-D36.

23. da Huang W, Sherman BT, Lempicki RA: Systematic and integrative analysis of large gene lists using DAVID bioinformatics resources. Nat Protoc 2009, 4(1):44-57.
24. Bohlig L, Metzger R, Rother K, Till H, Engeland K: The CCN3 gene coding for an extracellular adhesion-related protein is transcriptionally activated by the p53 tumor suppressor. Cell Cycle 2008, 7(9):1254-1261.

25. Doghman M, Arhatte M, Thibout H, Rodrigues G, De Moura J, Grosso S, West AN, Laurent M, Mas JC, Bongain A, Zambetti GP, Figueiredo BC, Auberger P, Martinerie C, Lalli E: Nephroblastoma overexpressed/cysteine-rich protein 61/ connective tissue growth factor/nephroblastoma overexpressed gene-3 (NOV/CCN3), a selective adrenocortical cell proapoptotic factor, is down-regulated in childhood adrenocortical tumors. J Clin Endocrinol Metab 2007, 92(8):3253-3260.

26. Fukunaga-Kalabis M, Martinez G, Telson SM, Liu ZJ, Balint K, Juhasz I, Elder $D E$, Perbal B, Herlyn M: Downregulation of CCN3 expression as a potential mechanism for melanoma progression. Oncogene 2008, 27(18):2552-2560.

27. Ouellet V, Tiedemann K, Mourskaia A, Fong JE, Tran-Thanh D, Amir E, Clemons M, Perbal B, Komarova SV, Siegel PM: CCN3 impairs osteoblast and stimulates osteoclast differentiation to favor breast cancer metastasis to bone. Am J Pathol 2011, 178(5):2377-2388.

28. Sin WC, Tse M, Planque N, Perbal B, Lampe PD, Naus CC: Matricellular protein $\mathrm{CCN} 3(\mathrm{NOV})$ regulates actin cytoskeleton reorganization. J Biol Chem 2009, 284(43):29935-29944.

29. Wu Q, Maniatis T: A striking organization of a large family of human neural cadherin-like cell adhesion genes. Cell 1999, 97(6):779-790.

30. Gaziel-Sovran A, Segura MF, Di Micco R, Collins MK, Hanniford D, de Vega-Saenz Miera E, Rakus JF, Dankert JF, Shang S, Kerbel RS, Bhardwaj N, Shao Y, Danvishian F, Zavadil J, Erlebacher A, Mahal LK, Osman I, Hernando E: miR-30b/30d regulation of GalNAc transferases enhances invasion and immunosuppression during metastasis. Cancer Cell 2011, 20(1):104-118.

31. Palmgren $S$, Vartiainen $M$, Lappalainen P: Twinfilin, a molecular mailman for actin monomers. J Cell Sci 2002, 115(Pt 5):881-886.

32. Helfer $E$, Nevalainen EM, Naumanen $P$, Romero $S$, Didry D, Pantaloni $D$, Lappalainen P, Carlier MF: Mammalian twinfilin sequesters ADP-G-actin and caps filament barbed ends: implications in motility. EMBO J 2006, 25(6):1184-1195.

33. Lo KW, Kogoy JM, Pfister KK: The DYNLT3 light chain directly links cytoplasmic dynein to a spindle checkpoint protein, Bub3. J Biol Chem 2007, 282(15):11205-11212.

34. Yeh TY, Chuang JZ, Sung CH: Dynein light chain rp3 acts as a nuclear matrix-associated transcriptional modulator in a dynein-independent pathway. J Cell Sci 2005, 118(Pt 15):3431-3443.

35. Kim BG, Lee JH, Yasuda J, Ryoo HM, Cho JY: Phospho-Smad1 modulation by nedd4 E3 ligase in BMP/TGF-beta signaling. J Bone Miner Res 2011, 26(7):1411-1424.

36. Amodio N, Scrima M, Palaia L, Salman AN, Quintiero A, Franco R, Botti G, Pirozzi P, Rocco G, De Rosa N, Viglietto G: Oncogenic role of the E3 ubiquitin ligase NEDD4-1, a PTEN negative regulator, in non-small-cell lung carcinomas. Am J Pathol 2010, 177(5):2622-2634.

37. Chung S, Nakashima M, Zembutsu H, Nakamura Y: Possible involvement of NEDD4 in keloid formation; its critical role in fibroblast proliferation and collagen production. Proc Jpn Acad Ser B Phys Biol Sci 2011, 87(8):563-573.

38. Mansbridge JN, Knuchel R, Knapp AM, Sutherland RM: Importance of tyrosine phosphatases in the effects of cell-cell contact and microenvironments on EGF-stimulated tyrosine phosphorylation. J Cell Physiol 1992, 151(3):433-442.

39. Retta SF, Barry ST, Critchley DR, Defilippi P, Silengo L, Tarone G: Focal adhesion and stress fiber formation is regulated by tyrosine phosphatase activity. Exp Cell Res 1996, 229(2):307-317.

40. Soler C, Rousselle P, Damour O: Cadherin mediated cell-cell adhesion is regulated by tyrosine phosphatases in human keratinocytes. Cell Adhes Commun 1998, 5(1):13-25.

41. Brennan $\mathrm{H}$, Smith S, Stoker A: Phosphotyrosine signalling as a regulator of neural crest cell adhesion and motility. Cell Motil Cytoskeleton 1999, 42(2):101-113.

42. Pilecka I, Patrignani C, Pescini R, Curchod ML, Perrin D, Xue Y, Yasenchak J, Clark A, Magnone MC, Zaratin P, Valenzuela D, Rommel C, Hooft van Huijsduijnen R: Protein-tyrosine phosphatase $\mathrm{H} 1$ controls growth hormone receptor signaling and systemic growth. J Biol Chem 2007, 282(48):35405-35415.

43. Zhi HY, Hou SW, Li RS, Basir Z, Xiang Q, Szabo A, Chen G: PTPH1 cooperates with vitamin $D$ receptor to stimulate breast cancer growth through their mutual stabilization. Oncogene 2011, 30(14):1706-1715.

44. Sagane K, Ohya Y, Hasegawa Y, Tanaka I: Metalloproteinase-like, disintegrin-like, cysteine-rich proteins MDC2 and MDC3: novel human cellular disintegrins highly expressed in the brain. Biochem J 1998, 334(Pt 1):93-98. 
45. Zhu P, Sang Y, Xu H, Zhao J, Xu R, Sun Y, Xu T, Wang X, Chen L, Feng H, Li C, Zhao S: ADAM22 plays an important role in cell adhesion and spreading with the assistance of 14-3-3. Biochem Biophys Res Commun 2005, 331(4):938-946.

46. McCartan D, Bolger JC, Fagan A, Byrne C, Hao Y, Qin L, Mcllroy M, Xu J, Hill AD, Gaora PO, Young LS: Global characterization of the SRC-1 transcriptome identifies ADAM22 as an ER-independent mediator of endocrine-resistant breast cancer. Cancer Res 2012, 72(1):220-229.

47. Tzeng HE, Chen JC, Tsai CH, Kuo CC, Hsu HC, Hwang WL, Fong YC, Tang CH: CCN3 increases cell motility and MMP-13 expression in human chondrosarcoma through integrin-dependent pathway. J Cell Physiol 2011, 226(12):3181-3189.

48. Tan TW, Huang YL, Chang JT, Lin JJ, Fong YC, Kuo CC, Tsai CH, Chen YJ, Hsu HC, Cho DY, Chen YH, Tang CH: CCN3 increases BMP-4 expression and bone mineralization in osteoblasts. J Cell Physiol 2012, 227(6):2531-2541.

49. Ghayad SE, Vendrell JA, Bieche I, Spyratos F, Dumontet C, Treilleux I, Lidereau R, Cohen PA: Identification of TACC1, NOV, and PTTG1 as new candidate genes associated with endocrine therapy resistance in breast cancer. J Mol Endocrinol 2009, 42(2):87-103.

50. Jiang WG, Watkins G, Fodstad O, Douglas-Jones A, Mokbel K, Mansel RE: Differential expression of the CCN family members Cyr61, CTGF and Nov in human breast cancer. Endocrine-Related Cancer 2004, 11(4):781-791.

51. Bustin SA, Benes V, Garson JA, Hellemans J, Huggett J, Kubista M, Mueller R, Nolan T, Pfaffl MW, Shipley GL, Vandesompele J, Wittwer CT: The MIQE guidelines: minimum information for publication of quantitative real-time PCR experiments. Clin Chem 2009, 55(4):611-622

52. Betel D, Koppal A, Agius P, Sander C, Leslie C: Comprehensive modeling of microRNA targets predicts functional non-conserved and non-canonical sites. Genome Biol 2010, 11(8):R90.

53. Pratap J, Wixted JJ, Gaur T, Zaidi SK, Dobson J, Gokul KD, Hussain S, van Wijnen AJ, Stein JL, Stein GS, Lian JB: Runx2 transcriptional activation of Indian Hedgehog and a downstream bone metastatic pathway in breast cancer cells. Cancer Res 2008, 68(19):7795-7802.

54. Javed A, Barnes GL, Pratap J, Antkowiak T, Gerstenfeld LC, van Wijnen AJ, Stein JL, Lian JB, Stein GS: Impaired intranuclear trafficking of Runx2 (AML3/CBFA1) transcription factors in breast cancer cells inhibits osteolysis in vivo. Proc Natl Acad Sci U S A 2005, 102(5):1454-1459.

55. Barnes GL, Hebert KE, Kamal M, Javed A, Einhorn TA, Lian JB, Stein GS, Gerstenfeld LC: Fidelity of Runx2 activity in breast cancer cells is required for the generation of metastases-associated osteolytic disease. Cancer Res 2004, 64(13):4506-4513.

56. Pande S, Browne G, Padmanabhan S, Zaidi SK, Lian JB, van Wijnen AJ, Stein JL, Stein GS: Oncogenic cooperation between PI3K/Akt signaling and transcription factor Runx2 promotes the invasive properties of metastatic breast cancer cells. J Cell Physiol 2013, 228(8):1784-1792.

57. Ouzounova M, Vuong T, Ancey PB, Ferrand M, Durand G, Le-Calvez Kelm F, Croce C, Matar C, Herceg Z, Hernandez-Vargas H: MicroRNA miR-30 family regulates non-attachment growth of breast cancer cells. BMC Genomics 2013, 14:139.

58. Rodriguez-Gonzalez FG, Sieuwerts AM, Smid M, Look MP, Meijer-van Gelder ME, de Weerd V, Sleijfer S, Martens JW, Foekens JA: MicroRNA-30C expression level is an independent predictor of clinical benefit of endocrine therapy in advanced estrogen receptor positive breast cancer. Breast Cancer Res Treat 2011, 127(1):43-51.

59. Cheng CW, Wang HW, Chang CW, Chu HW, Chen CY, Yu JC, Chao Jl, Liu HF, Ding SL, Shen CY: MicroRNA-30a inhibits cell migration and invasion by downregulating vimentin expression and is a potential prognostic marker in breast cancer. Breast Cancer Res Treat 2012, 134(3):1081-1093.

60. Mathew LK, Lee SS, Skuli N, Rao S, Keith B, Nathanson KL, Lal P, Simon MC: Restricted expression of miR-30c-2-3p and miR-30a-3p in clear cell renal cell carcinomas enhances HIF2alpha activity. Cancer Discovery 2014, 4(1):53-60.

61. Ling XH, Han ZD, Xia D, He HC, Jiang FN, Lin ZY, Fu X, Deng YH, Dai QS, Cai C, Chen JH, Liang YX, Zhong WD, Wu CL: MicroRNA-30c serves as an independent biochemical recurrence predictor and potential tumor suppressor for prostate cancer. Mol Biol Rep 2014, 41(5):2779-2788.

62. Kong $X, X u X$, Yan Y, Guo F, Li J, Hu Y, Zhou H, Xun Q: Estrogen regulates the tumour suppressor MiRNA-30c and its target gene, MTA-1, in endometrial cancer. PLoS One 2014, 9(3):e90810.
63. Li J, Donath S, Li Y, Qin D, Prabhakar BS, Li P: miR-30 regulates mitochondrial fission through targeting p53 and the dynamin-related protein-1 pathway. PLoS Genet 2010, 6(1):e1000795.

64. Jia W, Eneh JO, Ratnaparkhe S, Altman MK, Murph MM: MicroRNA-30c-2* expressed in ovarian cancer cells suppresses growth factor-induced cellular proliferation and downregulates the oncogene BCL9. Mol Cancer Res 2011, 9(12):1732-1745

65. Brinkley BR, Beall PT, Wible $L$, Mace ML, Turner DS, Cailleau RM: Variations in cell form and cytoskeleton in human breast carcinoma cells in vitro. Cancer Res 1980, 40(9):3118-3129.

66. Riaz M, van Jaarsveld MT, Hollestelle A, der Prager-van Smissen WJ, Heine AA, Boersma AW, Liu J, Helmijr J, Ozturk B, Smid M, Wiemer EA, Foekens JA, Martens JW: miRNA expression profiling of 51 human breast cancer cell lines reveals subtype and driver mutation-specific miRNAs. Breast Cancer Res 2013, 15(2):R33.

67. Volinia S, Croce CM: Prognostic microRNA/mRNA signature from the integrated analysis of patients with invasive breast cancer. Proc Natl Acad Sci U S A 2013, 110(18):7413-7417.

68. Enerly E, Steinfeld I, Kleivi K, Leivonen SK, Aure MR, Russnes HG, Ronneberg JA, Johnsen $H$, Navon $R$, Rodland $E$, Mäkelä R, Naume B, Perälä $M$, Kallioniemi O, Kristensen VN, Yakhini Z, Børresen-Dale AL: miRNA-mRNA integrated analysis reveals roles for miRNAs in primary breast tumors. PLoS One 2011, 6(2):e16915

69. Farazi TA, Horlings HM, Ten Hoeve JJ, Mihailovic A, Halfwerk H, Morozov P, Brown M, Hafner M, Reyal F, van Kouwenhove M, Kreike B, Sie D, Hovestadt $V$, Wessels LF, van de Vijver MJ, Tuschl T: MicroRNA sequence and expression analysis in breast tumors by deep sequencing. Cancer Res 2011, 71(13):4443-4453.

70. Foekens JA, Sieuwerts AM, Smid M, Look MP, de Weerd V, Boersma AW, Klijn JG, Wiemer EA, Martens JW: Four miRNAs associated with aggressiveness of lymph node-negative, estrogen receptor-positive human breast cancer. Proc Natl Acad Sci U S A 2008, 105(35):13021-13026.

71. Brigstock DR: The CCN family: a new stimulus package. J Endocrinol 2003, 178(2):169-175.

72. Vallacchi V, Daniotti M, Ratti F, Di Stasi D, Deho P, De Filippo A, Tragni G, Balsari A, Carbone A, Rivoltini L, Parmiani G, Lazar N, Perbal B, Rodolfo M: CCN3/nephroblastoma overexpressed matricellular protein regulates integrin expression, adhesion, and dissemination in melanoma. Cancer Res 2008, 68(3):715-723.

73. Benini S, Perbal B, Zambelli D, Colombo MP, Manara MC, Serra M, Parenza M, Martinez V, Picci P, Scotlandi K: In Ewing's sarcoma CCN3(NOV) inhibits proliferation while promoting migration and invasion of the same cell type. Oncogene 2005, 24(27):4349-4361.

74. Manara MC, Perbal B, Benini S, Strammiello R, Cerisano V, Perdichizzi S, Serra M, Astolfi A, Bertoni F, Alami J, Yeger H, Picci P, Scotlandi K: The expression of ccn3 (nov) gene in musculoskeletal tumors. Am J Pathol 2002, 160(3):849-859.

75. Sin WC, Bechberger JF, Rushlow WJ, Naus CC: Dose-dependent differential upregulation of CCN1/Cyr61 and CCN3/NOV by the gap junction protein Connexin43 in glioma cells. J Cell Biochem 2008, 103(6):1772-1782.

76. Fu CT, Bechberger JF, Ozog MA, Perbal B, Naus CC: CCN3 (NOV) interacts with connexin43 in C6 glioma cells: possible mechanism of connexin-mediated growth suppression. J Biol Chem 2004, 279(35):36943-36950.

77. Zhang Y, Wang C: Nephroblastoma overexpressed (NOV/CCN3) gene: a paired-domain-specific PAX3-FKHR transcription target that promotes survival and motility in alveolar rhabdomyosarcoma cells. Oncogene 2011, 30(32):3549-3562.

\section{doi:10.1186/s12935-014-0073-0}

Cite this article as: Dobson et al:: hsa-mir-30c promotes the invasive phenotype of metastatic breast cancer cells by targeting NOV/CCN3. Cancer Cell International 2014 14:73. 